DOI: https://doi.org/10.33330/jurteksi.v6i2.552

Available online at http://jurnal.stmikroyal.ac.id/index.php/jurteksi

\title{
PERANCANGAN SISTEM INFORMASI PENJUALAN CV MITRA TANI MENGGUNAKAN METODE PROTOTYPE
}

\author{
Hermanda Ihut Tua Simamora \\ Prodi Pendidikan Musik Gereja, Institut Agama Kristen Negeri Tarutung \\ email: hermandas41@gmail.com
}

\begin{abstract}
Information technology produces innovation, which can be the initial stage of the success of any business. Many businesses use the sales information system in daily sales. Using a sales information system can improve the effective and efficient procedure of working, as well as system easy to generate sales data, price information, inventory data, and invoice. Business process in CV Mitra Tani still manual, where is price information writes on paper and there is no sales data, inventory data, and invoice. Problems using manual business processes faced by CV Mitra Tani are needed a long time to serve customers, there is no data used to know profit loss, and there is no data used to decide between stocking. To solve this problem, CV Mitra Tani will develop a sales information system based on the web. The features of the build system generate sales data, inventory data, price information, and print invoice. The system will be developed by using prototype methodology dan built-in PHP language, while the database will use MySQL. Based on the research, using a sales information system can be useful to improve the efficiency and effectiveness of the procedure sales business processes, by easily know information price, generate sales data, inventory data, and print invoice.
\end{abstract}

Keywords: MySQL; PHP; Prototype; Sales Information System;

\begin{abstract}
Abstrak: Teknologi informasi mendorong inovasi dan inovasi adalah jalan menuju kesuksesan sebuah bisnis. Banyak bisnis yang menggunakan sistem informasi penjualan dalam penjualan sehari-harinya. Penggunaan sistem informasi penjualan akan meningkatkan efektivitas dan effesiensi dalam proses kerja, seperti kemudahan dalam menghasilkan laporan penjualan, data inventaris, informasi harga dan cetak faktur. CV Mitra Tani adalah salah satu mini market yang menjual kebutuhan sehari-hari masyarakat. Bisnis proses yang ada di CV Mitra Tani masih manual, dimana informasi harga masih dicatat di buku, tidak ada data penjualan, inventaris dan tidak ada faktur. Masalah yang dihadapi oleh CV Mitra Tani dengan bisnis proses yang masih manual adalah waktu yang dibutuhkan untuk melayani pelanggan lama, tidak ada data yang dapat digunakan untuk mengetahui untung atau rugi, dan ketika melakukan stok barang tidak ada. Permasalahan tersebut akan diatasi oleh CV Mitra Tani dengan membangun sistem informasi penjualan berbasis web. fitur dari sistem yang akan dibangun adalah menghasilkan data penjualan, inventaris barang, informasi harga, dan cetak faktur. Sistem akan dikembangkan menggunakan metode prototype dan bahasa pemograman PHP, sedangkan databasenya akan menggunakan MyQL. Berdasarkan penelitian, penggunaan sistem informasi penjualan dapat meningkatkan efektitivitas dan efesiensi Cara kerja bisnis proses, seperti kemudahan dalam mengetahui harga, kemudahan menghasilkan laporan penjualan, inventasi dan kemudahan dalam mencetak faktur.
\end{abstract}

Kata kunci: MySQL; PHP; Prototype; Sistem Informasi Penjualan; 
JURTEKSI (Jurnal Teknologi dan Sistem Informasi)

Vol. 6 No. 2, April 2020, hlm. 173 - 178

DOI: https://doi.org/10.33330/jurteksi.v6i2.552

Available online at http://jurnal.stmikroyal.ac.id/index.php/jurteksi
ISSN 2407-1811 (Print)

ISSN 2550-0201 (Online)

\section{PENDAHULUAN}

Perkembangan teknologi informasi berjalan sangat pesat sehingga membawa manusia kedalam dunia baru, dimana teknologi telah mempengaruhi setiap aspek kehidupan, seperti bidang ekonomi, pendidikan, hiburan dan lainlain[1]. Berbagai pihak berusaha dan bersaing untuk menjadi terdepan dalam penguasaan teknologi informasi dan komuniasi terutama dalam penerapan teknologi komunikasi jarak jauh dan akses informasi [2]. Dengan perkembangan teknologi ini sangat membantu setiap orang dalam menyelesaikan masalah yang dihadapi, salah satunya adalah dibidang bisnis. Pada saat ini, bisnis tidak dapat dilepaskan lagi dari teknologi karena dengan penggunaan teknologi produkvitas bisnis dapat meningkat, serta proses penyelesaian pekerjaan lebih cepat dan tepat[3]. Perkembangan teknologi informasi berperan besar dalam perubahan arah dan visi perusahaan guna meningkatkan pendapatannya, dengan demikian teknik penjualan dan administrasi harus diperbaiki dengan sentuhan teknologi informasi[4].

Salah satu contoh penerapan teknologi informasi yang banyak dilakukan dibidang bisnis adalah penerepan sistem informasi penjualan berbasis web. Hal ini disebabkan karena dengan pengggunaan sistem informasi berbasis web, maka pencarian informasi lebih cepat, hilangnya redundansi, meminimalisir kesalahan manusia, serta data selalu diperbaharui[5]. Penggunaan aplikasi berbasis web dikatakan lebih efektif dan effesien karena adanya kemudahan dalam pengaksesan dan penyampaian informasi[6].

CV Mitra Tani merupakan sebuah mini market yang menjual kebutuhan pokok masyarakat sehari-hari di kota medan. Hingga saat ini, penyetokan barang masih dilakukan secara manual dimana data barang akan dicatat didalam sebuah buku. Proses transaksi dilakukan dengan menggunakan nota penjualan dan akan direkap dalam sebuah buku besar. Dengan penyetokan dan nota penjualan yang masih manual, dapat menimbulkan kendala yang membuat proses pencarian barang menjadi lama dan informasi persediaan stok kurang akurat[7]. Selain kendala tersebut, permasalahan yang dihadapi oleh CV Mitra Tani yaitu tidak ada ketentuan dalam penentuan harga jual sebuah produk, sehingga harga sebuah produk bisa berbeda-beda. Hal ini menim-bulkan permasalahan karena menye-babkan kekeliruan maupun kesalahan dalam pembuatan laporan . Selain itu, data penjualan yang ada pada nota tidak langsung direkap kedalam buku besar, sehingga mengakibatkan banyak data penjualan yang hilang. Untuk menyelesaikan permasalahan diatas maka diusulkan sebuah sistem informasi penjualan yang diharapkan dapat mempermudah dalam pengolahan data transaksi pembelian, penjualan serta pembuatan laporan pada CV Mitra Masyarakat.

Tujaun dari penelitian ini adalah untuk menghasilkan sebuah sistem informasi penjualan yang dapat mengatasi permasalahan di CV Mitra Tani. Dengan penggunaan sistem informasi penjualan tersebut, maka akan memberikan kemudahan bagi pengguna dalam membuat laporan data penjualan, data stok barang dan mencetak bukti atau struk hasil transaksi pembayaran[8].

Dalam pengembangan sistem, metode yang digunakan adalah prototype. Prototype merupakan salah satu model yang digunakan untuk mensimulasikan sebuah program oleh developer kepada 
JURTEKSI (Jurnal Teknologi dan Sistem Informasi)

Vol. 6 No. 2, April 2020, hlm. 173 - 178

DOI: https://doi.org/10.33330/jurteksi.v6i2.552

Available online at http://jurnal.stmikroyal.ac.id/index.php/jurteksi
ISSN 2407-1811 (Print)

ISSN 2550-0201 (Online) pengguna untuk memahami program yang sesuai dengan kebutuhan pengguna tersebut [9]. Bahasa pemograman yang digunakan adalah PHP dan databasenya adalah MySQL. PHP merupakan sebuah pemograman script yang dapat digunakan dalam pengolahan data serta mengirimnya kembali ke browser dalam bentuk kode HTML [10]. Sedangkan MySQL merupakan software basis data yang mengandung sejumlah tabel data [10].

\section{METODE}

Penelitian dilakukan pada CV Mitra Tani yang terletak di jalan $\mathrm{Jl}$. Jamin Ginting km 10 no 126, Kota Medan, Sumatera Utara 20222.

Dalam penelitian ini, dilakukan pengumpulan data dengan teknik:

- Pengamatan yaitu dilakukan langsung melakukan pengamatan ke CV Mitra Tani untuk mencari data dan informasi yang akan digunakan serta melakukan pengamata terhadap proses yang berlangsung.

- Wawancara yaitu melakukan wawancara kepada pemilik dan karyawan CV Mitra Tani untuk memperoleh informasi tentang bisnis proses di $\mathrm{CV}$ Mitra Tani.

- Studi Literatur yaitu mencari sumber referensi dari jurnal, buku, skripsi, thesis dan disertasi yang mendukung penelitian ini.

Dalam sebuah penelitian dibutuhkan sebuah diagram alir yang akan menjadi panduan selama proses penelitian. Penelitian ini dimulai dari penentuan objek dan lokasi penelitian kemudian mengidentifikasi masalah, membuat rumusan dan batasan masalah agar masalah yang diteliti jelas serta tidak menyimpang dari permasalahan dan menentukan tujuan dan kegunaan penelitian agar penelitian ini berjalan dengan semestinya. Dilakukan pengumpulan data yang digunakan dalam mengolah dan menganalisa data serta menyusun rancangan penelitian dan menetapkan hasil penelitian serta membuat laporan hasil penelitian. Berikut ini merupakan diagram alir penelitian yang akan dilakukan.

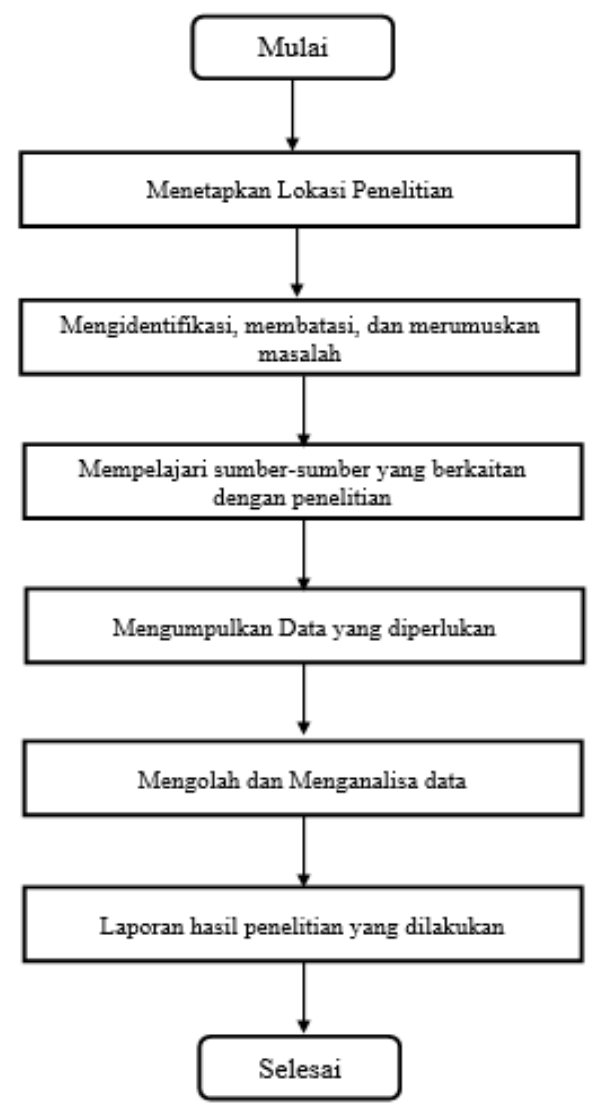

Gambar 1 Diagram Alir Penelitian

\section{HASIL DAN PEMBAHASAN}

Setelah dilakukan analisis maka didesain sistem yang dibangun kemudian melakukan dimplementasikan kedalam bentuk program menggunakan bahasa pemogramana PHP dan MySQL. Untuk 
JURTEKSI (Jurnal Teknologi dan Sistem Informasi)

Vol. 6 No. 2, April 2020, hlm. 173 - 178

DOI: https://doi.org/10.33330/jurteksi.v6i2.552

Available online at http://jurnal.stmikroyal.ac.id/index.php/jurteksi

memastikan sistem dikembangkan berdasarkan dengan kebutuhan, maka akan dilakukan testing program. Pada tahap desain maka dilakukan sebuah pemodelan sistem menggunakan Unified Model Language (UML).

\section{Use Case Diagram}

Didalam sebuah diagram use case terdapat beberapa proses yang dapat dilakukan oleh aktor pada sebuah sistem. Oleh karena itu, use case diagram ini lebih fokus pada fungsionalitas yang terdapat dalam sistem bukan berdasarkan kejadian ataupun alur. Use case diagram akan menggambarkan hubungan diantara aktor dan sistem. Use case diagram sistem informasi penjualan CV Mitra Tani terdapat pada gambar 2 .

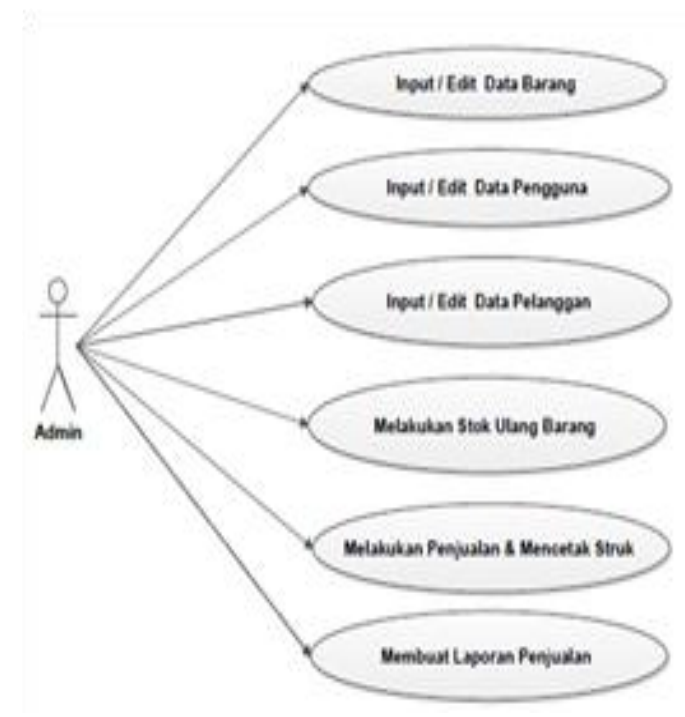

Gambar 2. Usecase Administrator

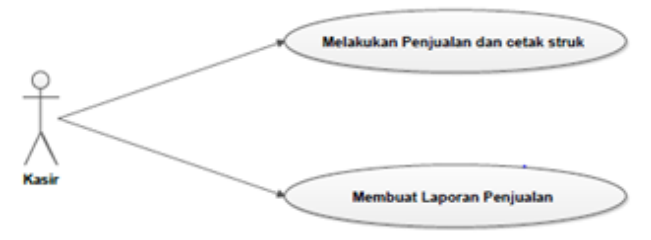

Gambar 3. Usecase Kasir pada gambar 6 ,
ISSN 2407-1811 (Print)

ISSN 2550-0201 (Online)

\section{Impementasi Program}

Login sebagai langkah awal administrator untuk melakukan edit barang atau penjualan.Dengan cara memasukkan nama dan password lalu akan masuk ke dalam halaman home dari web. Tampilan halaman login Web tertuang pada gambar 5 .

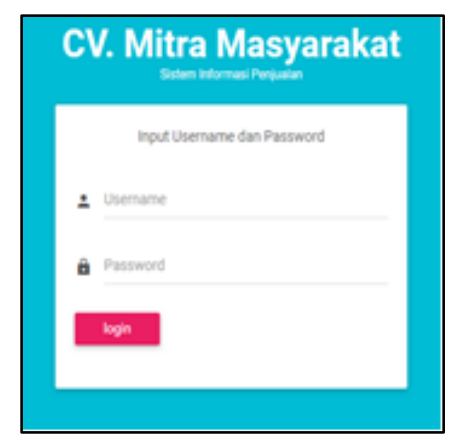

\section{Gambar 5 Halaman Login}

Halaman home adalah halaman awal dari web, dimana berfungsi sebagai integrasi antara halaman satu ke halaman yang lain. Halaman home Web tertuang

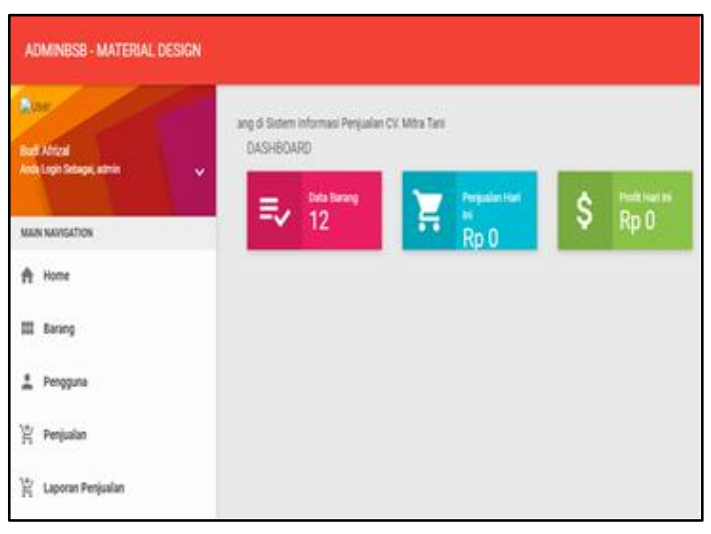

Gambar 6. Halaman Home

Halaman barang bertujuan untuk agar administrator dapat memasukkan data barang, edit barang,dan stok barang. 
JURTEKSI (Jurnal Teknologi dan Sistem Informasi)

Vol. 6 No. 2, April 2020, hlm. 173 - 178

DOI: https://doi.org/10.33330/jurteksi.v6i2.552

Available online at http://jurnal.stmikroyal.ac.id/index.php/jurteksi

Gambar halaman barang Web pada gambar 7.

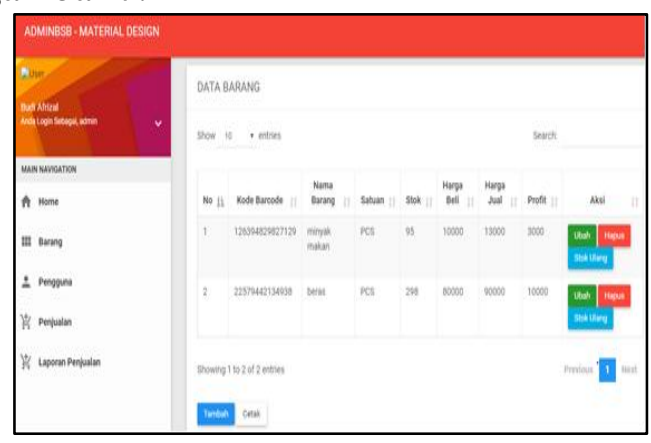

Gambar 7. Halaman Barang

Halaman pengguna bertujuan untuk administror agar dapat melakukan edit data dari sipengguna seperti data admin dan kasir. Gambar halaman pengguna web pada gambar 8 .

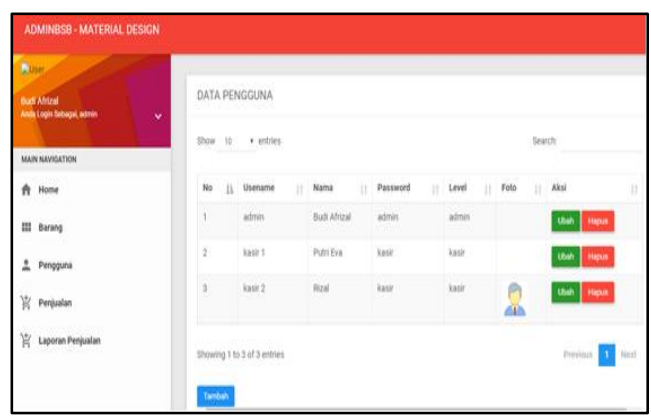

Gambar 8. Halaman Pengguna

Halaman penjualan bertujuan untuk administrator melakukan transaksi jual beli barang, dan mencetak struk pembelian. Gambar halaman penjualan Web pada gambar 6 . 
Available online at http://jurnal.stmikroyal.ac.id/index.php/jurteksi

datanya secara ototmatis digenerate oleh sistem. Waktu yang dibutuhkan untuk melayani pembeli lebih cepat karena tidak perlu lagi tulis tangan di bon faktur, serta dapat diketahui barang yang paling laku dan kurang laku sehingga dapat digunakan dalam strategi stok barang.

\section{DAFTAR PUSTAKA}

Marijan and Siti Nurajizah, "PERANCANGAN SISTEM INFORMASI AKADEMIK BERBASIS WEB PADA SD ISLAM LUQMANUL HAKIM BEKASI," vol. VI, no. 1, pp. 7178, 2019. DOI

10.33330/jurteksi.v6i1.399

[2] A. Hakim, H. Saragih, and A. Suharto, "EVALUASI TATA KELOLA TEKNOLOGI INFORMASI DENGAN FRAMWORK COBIT. 5 DI KEMENTERIAN ESDM," J. Sist. Inf., vol. 10, no. 2, p. 105, Jan. 2015. DOI

10.21609/jsi.v10i2.393

[3] A. Anthony, A. R. Tanaamah, and A. F. Wijaya, "Analisis Dan Perancangan Sistem Informasi Penjualan Berdasarkan Stok Gudang Berbasis Client Server (Studi Kasus Toko Grosir 'Restu Anda')," J. Teknol. Inf. dan Ilmu Komput., vol. 4, no. 2, p. 136, May 2017. DOI

10.25126/jtiik.201742321

[4] A. Irawan et al., "Perancangan Sistem Informasi Penjualan Pakaian Pada $\mathrm{Cv}$ Nonninth Inc Berbasis Online," J. Positif, vol. 3, no. 2, pp. 74-82, 2017. DOI : 10.31961/positif.v3i2.417

[5] M. Masrur, N. A. Mustofa, and M.
Sofanni, "Rancang Bangun Sistem Informasi Pengelolaan Kendaraan di PT PLN (Persero) Area Mojokerto," Regist. J. Ilm. Teknol. Sist. Inf., vol. 1, no. 1, p. 24, 2015. DOI : $10.26594 /$ register.v1i1.403

[6] M. Siddik and A. Nasution, "Perancangan Aplikasi Push Notification Berbasis Android," Jurteksi, vol. 4, no. 2, pp. 149154, 2018. DOI : 10.33330/jurteksi.v4i2.56

[7] Khaasanah, Arif Syaeffudin Habsi, Imam Maliki, Y. M. Liu, and Ismail, "RANCANG BANGUN ADMIISTRASI STOK COUPLER PT KOMPACINDO AREA UTAMA," Jurteksi, vol. VI, no. 1, pp. 25-34, 2019. DOI : 10.1017/CBO9781107415324.004

[8] A. S. Andeh Lukito, Sharipuddin, "Analisis Dan Perancangan Aplikasi Penjualan Pada Toko Lovable Berbasis Android," J. Ilm. Media Process., vol. 10, no. 2, pp. 476-483, 2015. Link : http://ejournal.stikomdb.ac.id/index.php/processor/articl e/view/103

[9] D. A. Firmansyah, Yoki, Reza Maulana, "Prototipe sistem informasi pelelangan barang berbasis web sebagai media pengolah informasi data pelelangan," J. Khatulistiwa Inform., vol. VII, no. 2, pp. 134140, 2019. DOI : 10.31294/jki.v7i2.6655.g3753

[10] A. Firman, H. F. Wowor, X. Najoan, J. Teknik, E. Fakultas, and T. Unsrat, "Sistem Informasi Perpustakaan Online Berbasis Web," E-Journal Tek. Elektro Dan Komput., vol. 5, no. 2, pp. 29-36, $2016 . \quad$ DOI 10.35793/jtek.5.2.2016.11657 